\title{
Las exequias de Felipe V en Panamá. Un grabado inédito
}

\author{
Manuel Gámez Casado \\ Universidad de Sevilla \\ mgamez@us.es
}

De manera recurrente la Corona española utilizó la celebración de fiestas para difundir un discurso político que facilitase la articulación del vasto continente americano. La organización de festejos fue un extraordinario medio persuasivo para consolidar su autoridad sobre las Indias. De hecho, fueron una exteriorización de su poder que se materializó en la erección de túmulos, decorados y construcciones efímeras que transformaron temporalmente plazas y vías públicas, así como catedrales e iglesias (Bonet, 1990: 5). Al respecto, es interesante comprobar cómo se adaptaban a la sociedad americana unas festividades bien consolidadas en Europa, y en las que se recurrió a textos y grabados de diversa procedencia que tuvieron un extraordinario éxito en el Nuevo Mundo. Estos diseños servían de base a escenografías, enriquecidas con complejos programas iconográficos conformados por pinturas y esculturas que representaban emblemas y jeroglíficos destinados a propagar las hazañas y virtudes del protagonista de la fiesta (Domínguez, 1996: 36-70). De ello se ha dado buena cuenta en los estudios que sobre la fiesta en los virreinatos americanos se han publicado recientemente, dándose a conocer no solo interesantes testimonios y descripciones de dichas festividades, sino también estampas que recogen las decoraciones temporales levantadas en las distintas ciudades ${ }^{1}$. Así, son numerosas las aportaciones que sobre el particular se han publicado acerca de los virreinatos de la Nueva España y del Perú, pero la circunstancia cambia si se contabilizan los estudios que sobre la Nueva Granada han ido apareciendo, siendo aún escasas las noticias que tenemos sobre los festejos celebrados en el nuevo reino granadino.

La insuficiente presencia de ese material gráfico en los contextos europeos se ha achacado a la falta de grabados que permitiesen divulgar las festividades neogranadinas, frente a lo que ocurrió en los casos mexicanos o peruanos
(Rodríguez y Mínguez, 2012: 115-143). Precisamente por esta carencia de estampas resulta extraordinaria la localización en el Archivo General de la Nación de Colombia del Grabado que junto a su correspondiente expediente, recogen las exequias celebradas por la muerte de Felipe $V$ en la parroquia de Santa Ana de la ciudad de Panamá, templo que por entonces cumplía la función de catedral metropolitana. Esta nueva imagen debe ser comparada con la estampa que sobre el mismo tema ya fue publicada, pues entre ellas existen diferencias ${ }^{2}$.

En lo que a funerales se refiere, el caso neogranadino destaca por contar con varias estampas que demuestran la importancia de estas festividades, acogiendo una tradición ya consolidada en México y Perú desde el siglo XVI (Mejías, 1996: 21-41 y Rodríguez y Mínguez, 2012: 127). De entre todas, cabe destacar el túmulo levantado en la parroquia de Santa Ana en 1748 con motivo de la muerte del rey Felipe V. Ciertamente, la imagen del catafalco se conocía gracias a la publicación de una estampa conservada en el Archivo General de Indias, siendo hasta ahora el único testimonio gráfico existente sobre la celebración de exequias en la capital panameña [1]. A este grabado se debe sumar ahora el localizado en el archivo bogotano y dado aquí a conocer.

Así, el 9 de julio de 1746 fallecía el rey Felipe V en Madrid tras haber protagonizado un reinado convulso. De inmediato, el marqués de la Ensenada, secretario de Guerra y Marina, trasladó la noticia de tan trágico suceso al gobernador de Panamá Dionisio de Alcedo y Herrera mediante una carta fechada el 24 de agosto ${ }^{3}$. Como era habitual en estos escritos, hasta el momento inéditos junto a la estampa que ahora se publica, no solo se dio cuenta del fallecimiento del monarca y de la inminente exaltación al trono de su sucesor, sino que también se ordenó organizar las exequias y sufragios necesarios para honrar su memoria y demostrar la 


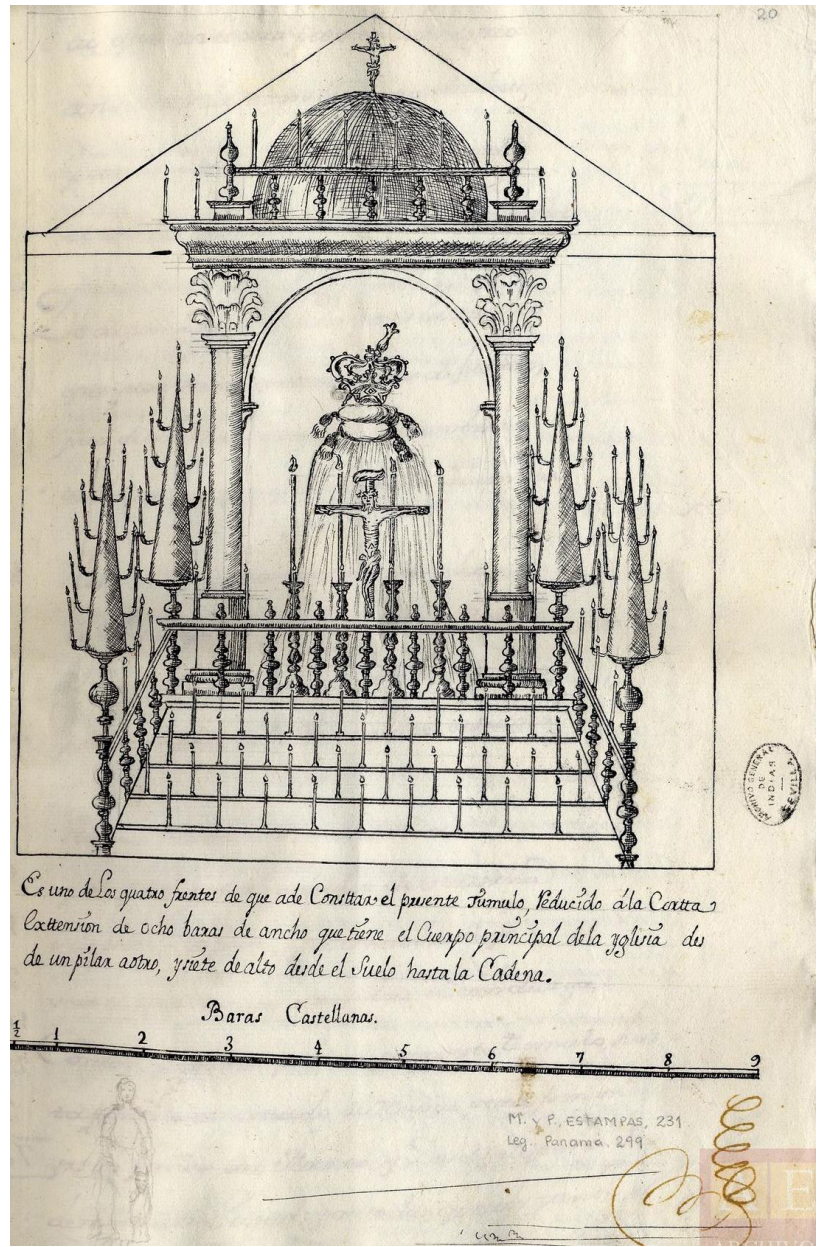

1. «Túmulo levantado en la iglesia de Santa Ana en función de catedral de Panamá con motivo de las exequias por Felipe V». 1747. Archivo General de Indias. Mapas, Planos, Documentos Iconográficos y Documentos Especiales. MP-Panamá, 231

lealtad de sus vasallos. De manera particular, se atendió al costo de tal celebración, pues debía ser asumido por la Junta de Hacienda de la Audiencia de Panamá y no por el gobierno virreinal.

No fue hasta marzo de 1747 cuando la Junta se reunió para organizar los funerales por Felipe V, acordándose que su inicio correspondiera al bando del gobernador anunciando la muerte del rey a la población, que debía vestir completamente de negro durante los cuatro meses de luto. Asimismo, el capitán de granaderos Fernando de Santos, sargento mayor de Panamá, se ocuparía de disparar desde el baluarte de San Francisco un cañón de a 18 cada cuarto de hora como honra militar hacia el monarca. Por su parte, las banderas se mantendrían arrolladas durante nueve días y los oficiales vestirían una banda negra como señal de luto durante la celebración de las exequias.

Sin embargo, el principal tema de discusión en la junta citada fue la construcción del túmulo para el monarca. Si bien es cierto que finalmente se aprobó la creación de una pira que cumpliese con las normas de decoro exigida para estos casos, pues debía estar ricamente adornada y enriquecida con telas y velas, parece que las limitaciones económicas impuestas por la Audiencia impidieron que se realizase una estructura de mayores dimensiones. Para cumplir con tales exigencias, se llamó al sobrestante de las reales fábricas Manuel Pinto de Acosta y al carpintero Bernabé Trujillo, quienes habían colaborado con el cabildo de la catedral en distintos trabajos, encomendándoseles en esta ocasión el diseño y fabricación del túmulo4. El lugar designado para levantarlo fue la parroquia de Santa Ana, que por entonces cumplía la función de catedral al no haberse finalizado las obras de ésta. Finalmente, el propio Pinto de Acosta presupuestó la construcción del monumento efímero en 9.374 pesos, sin incluir los paños del féretro, el dosel y las esculturas que remataban el templete.

La descripción del túmulo que el gobernador de Panamá realizó para conseguir la aprobación de las autoridades virreinales coincide con lo representado en la estampa del Archivo General de Indias ya publicada. Esta imagen muestra una estructura sencilla en forma de templete sostenido por cuatro columnas con capiteles corintios. Todo ello se eleva sobre un graderío formado por cuatro escaleras que incrementan la monumentalidad del conjunto, alcanzando en su cota más alta la techumbre de la parroquia, incluida en la representación. El túmulo destaca por su escasa decoración, la sencillez de sus soportes y la simplicidad de su cubierta, formada por una bóveda semiesférica retranqueada y a la que precede una balaustrada. Debajo de la bóveda y presidiendo el monumento se sitúa el catafalco real con la corona y el cetro sobre un almohadón. Es limitado el número de esculturas que jalonan el templete, pues tan solo se contabilizan dos crucificados, uno rematando la bóveda superior y otro entre cuatro candelabros sobre el graderío. Finalmente, unos hachones troncopiramidales dispuestos en las esquinas y portadores de numerosas velas servían para alumbrar el conjunto, rematando una estructura discre- 
ta pero que cumplía con las necesidades propias de la celebración.

A pesar de la fidelidad del dibujo descrito, considerado hasta ahora el único testimonio gráfico de unas exequias celebradas en Panamá, lo cierto es que ofrece importantes diferencias con el grabado ahora localizado en Bogotá correspondiente al túmulo real [2]. En lo que se refiere a la estructura, repite el modelo de templete que se terminará de consolidar durante el siglo XVIII en las celebraciones neogranadinas. No obstante, el del grabado aquí dado a conocer muestra una mayor complejidad ornamental. Así, el graderío ofrece decoración de motivos vegetales que convergen en el centro de la composición, elementos que se repiten en el trasdós de la bóveda, que en este caso se remata por una linterna, en sustitución del crucificado. También las columnas ofrecen diseños diferentes, pues si ambas coinciden en el orden corintio, las del nuevo grabado presentan fustes torsos que otorgan cierto dinamismo a la composición, siendo soportes poco habituales en los túmulos conocidos en América ${ }^{5}$. Por otra parte, según el expediente adjunto al grabado, el conjunto fue pintado de negro y blanco en alusión al luto requerido para la ceremonia, dorándose únicamente las molduras y los remates superiores.

No obstante, la principal disparidad existente entre ambos modelos aparece en las esculturas que los decoran. En el segundo dibujo se aprecian delante de las columnas dos figuras femeninas como personificación de Europa y Asia, por lo que en el lado opuesto se encontrarían África y América para completar la representación de los cuatro continentes. En el caso de la alegoría del continente europeo, se trata de una mujer ricamente vestida que señala con su mano la corona y el cetro del monarca, situándose en la parte inferior un caballo a menor escala. Asia es representada mediante una figura femenina ataviada con ricas telas y acompañada por un camello sentado. Por el otro frente del túmulo estarían las esculturas correspondientes a África y América, aunque en la estampa no se recogen. Según las que se han representado, parece que se tomaron los modelos iconográficos ofrecidos por Cesare Ripa en su lconología para personificar los cuatro continentes. Se trata de una prueba de la amplia difusión que tanto las ilustraciones, como el texto del autor italiano tuvieron en América. Además, debe destacarse que este túmulo es el único de cuantos se diseñaron en la Nueva Granada en el que se representan a los cuatro

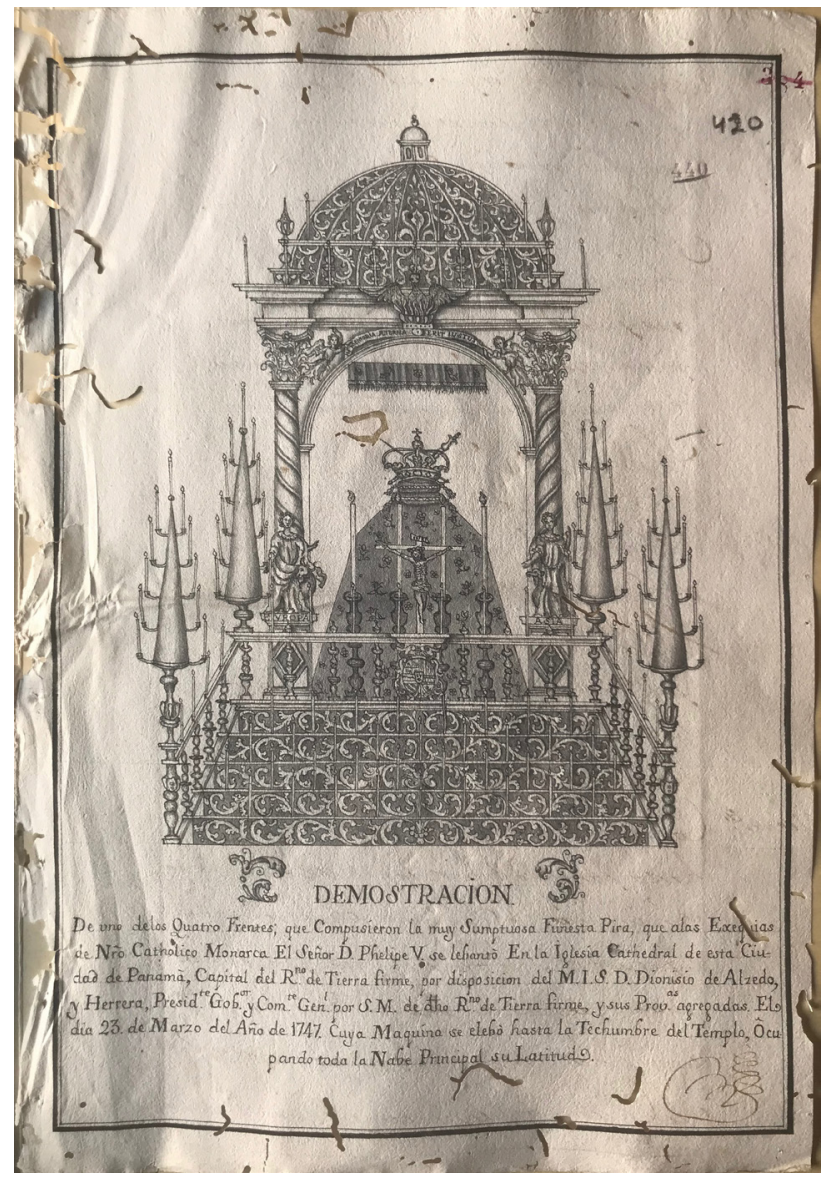

2. «Túmulo levantado en la iglesia de Santa Ana en función de catedral de Panamá con motivo de las exequias por Felipe V». 1747. Archivo General de la Nación de Colombia. Milicia y Marina. Leg. 112

continentes, a diferencia de lo que ocurrió en otros casos americanos (Morales, 2013: 399-410). Por otra parte, la representación de las cuatro partes del mundo flanqueando el sepulcro expresa el reinado del monarca sobre territorios de los cuatro continentes.

El programa iconográfico se completa con los ángeles situados en las enjutas del arco que sostienen una cartela en la que se puede leer la inscripción «Memoria eterna, erit iustus». Esta frase, empleada en el Réquiem del Salmo 111, alude a que el monarca sería siempre recordado por sus virtudes y justo reinado. La imagen del ave fénix situada en la clave del arco expresa el renacer del rey, en alusión a la continuidad de la dinastía borbónica en el trono español. Por último, en la estampa ahora localizada se representa sobre el catafalco un dosel, ennobleciendo el conjunto y 
ahondando en el privilegio de los monarcas españoles en su uso protocolario.

Con la construcción del túmulo de Felipe $\mathrm{V}$ en la iglesia de Santa Ana, la Audiencia de Panamá lograba equipararse en importancia política a otros territorios con mayor tradición en la organización de honras fúnebres por los reyes. En este sentido, si se compara el publicado junto a estas líneas con los realizados en ciudades como Quito o Lima dedicados al mismo monarca, se observa que si bien el panameño carece de la complejidad arquitectónica de éstos, ofrece un claro programa iconográfico que renueva el mensaje que las autoridades virreinales pretendían transmitir al pueblo. Con él, la Audiencia panameña, como otras instituciones americanas, demostraba en esa manifestación pública su fidelidad a la Corona, lo que explica la representación de las cuatro partes del mundo flanqueando el sepulcro del monarca, quien se erige como auténtico protector de cuantos territorios le pertenecían. Así, a través de la organización de este festejo y de la construcción del túmulo estudiado, cuya decoración recoge la tradición emblemática surgida en los albores del siglo XVI, se consiguió la integración de las distintas sociedades neogranadinas en una única realidad social, constituida en un solo virreinato e integrada en las ceremonias institucionales españolas consolidadas en América. Es en la plasmación gráfica de este contexto social donde reside la importancia de este hallazgo, aportándose un nuevo testimonio sobre las festividades celebradas en el Nuevo Reino de Granada.

\section{Notas}

1 El más completo estudio de cuantos se han publicado acerca de la fiesta barroca en Hispanoamérica fue el realizado por Mínguez, Rodríguez, González, Chiva, 2012.

2 Véase Mínguez, Rodríguez, González, Chiva, 2012: 201.

3 Archivo General de la Nación de Colombia, Bogotá (AGNC Bogotá), Milicia y Marina, Leg. 112, p. 366 rto.

4 AGNC Bogotá, Milicia y Marina, Leg. 112, p. 367 rto y vto.

5 Por ejemplificar algunos de los túmulos en los que se utilizaron las columnas torsas, véase el construido en honor de Fernando VI en la catedral de Guatemala y el diseñado para conmemorar la muerte de Felipe $V$ en la iglesia de Santiago de los Caballeros de la misma ciudad.

\section{Bibiliografía}

BONET CORREA, Antonio (1990), Fiesta, poder y arquitectura, Akal, Madrid.

DAIRON, Emilie (2002), «La primera flor de lis en los Andes: las exequias de Luis I en Santa Fe de Bogotá» en KOHUT, Karl y ROSE, Sonia (eds.), La formación de la cultura virreinal. El siglo XVIII, Vervuert, Madrid, pp. 185-204.

DOMíNGUEZ ORTIZ, Antonio (1996), La sociedad americana y la corona española en el siglo XVII, Marcial Pons, Madrid.

MEJÍAS, María Jesús (1996), "La muerte del Pontífice: las exequias del Papa Clemente XIV en Cartagena de Indias», Revista Ensayos del Instituto de Investigaciones Estéticas de la Facultad de Artes de la Universidad Nacional de Colombia, n. ${ }^{\circ}$ 4, pp. $21-41$.

MíNGUEZ, Víctor, RODRíGUEZ, Inmaculada, GONZÁLEZ, Pablo y CHIVA, Juan (2012), La fiesta barroca. Los virreinatos americanos (15601808), editorial Universitat Jaume I y editorial Universidad de las Palmas de Gran Canarias, Castellón de la Plana.

MORALES, José Miguel (2013), «La iconografía de los cuatro continentes. Creación de los modelos en Europa y su traslado a Hispanoamérica», en MARTÍNEZ PEREIRA, Ana, OSUNA, Inmaculada e INFANTES, Víctor (eds.), Palabras, símbolos, emblemas. Las estructuras gráficas de la representación, Turpin, Sociedad Española de Emblemática, Madrid, pp. 399-410.

RODRíGUEZ, Inmaculada y MíNGUEZ, Víctor (2012), «Cultura simbólica y fiestas borbónicas en Nueva Granada. De las exequias de Luis I (1724) a la proclamación de Fernando VII (1808)», C’S, n. 9, pp. 115-143. 